\title{
AS PRÁTICAS DISCURSIVAS TRANSLINGUAJEIRAS, TRANSCULTURAIS E DECOLONIAIS E AS (IN)VISIBILIDADES DAS IDENTIDADES PERFORMATIVAS DOS SUJEITOS NA SALA DE AULA DE LÍNGUA PORTUGUESA ADICIONAL EM CONTEXTO TRANSFRONTEIRIÇO
}

\author{
TRANSLINGUAL, TRANSCULTURAL AND DECOLONIAL DISCURSIVE PRACTICES
}

AND THE (IN)VISIBILITIES OF THE SUBJECTS' PERFORMATIVE IDENTITIES IN THE PORTUGUESE AS AN ADDITIONAL LANGUAGE CLASSROOM IN A TRANSBORDER CONTEXT

\author{
Henrique Rodrigues Leroy \\ Universidade Federal da Integração Latino-Americana \\ Maria Elena Pires Santos \\ Universidade Estadual do Oeste do Paraná
}

\begin{abstract}
RESUMO: $O$ presente artigo tem o objetivo de refletir sobre como as práticas translíngues (CANAGARAJAH, 2013; GARCÍA \& WEI, 2014), as transculturalidades (GUILHERME \& DIETZ, 2014; ORTíZ, 2002) e os estudos decoloniais (MIGNOLO, 2013) estão manifestados na sala de aula de Língua Portuguesa Adicional (PLA) em contexto transfronteiriço, na Universidade Federal da Integração Latino-Americana (UNILA) - localizada na cidade de Foz do Iguaçu, Paraná, Brasil, na Tríplice Fronteira com o Paraguai e a Argentina - e como tais manifestações podem (in)visibilizar as identidades performativas (PINTO, 2007) dos alunos e do professor. Tais práticas locais de linguagens foram concretizadas por meio de apresentações orais produzidas para um trabalho final na disciplina de Português Língua Adicional (PLA) que versou sobre a Guerra do Paraguai. Concluimos que as atividades aplicadas no contexto de sala de aula de PLA na UNILA puderam, por meio das práticas translinguajeiras, transculturais e decoloniais, recombinar, ressignificar e visibilizar as identidades performadas dos sujeitos aprendizes e do professor, abrindo possibilidades para que transitem por uma multiplicidade de terceiros lugares e terceiras margens, colaborando ativamente nas diversas redes configuradas pelos territórios transnacionais.
\end{abstract}

PALAVRAS-CHAVE: Estudos Decoloniais; Língua Portuguesa Adicional; Identidades Performativas; Transculturalidades; Translinguagens; UNILA.

ABSTRACT: The present article aims at reflecting about how translingual (CANAGARAJAH, 2013; GARCÍA \& WEI, 2014), transcultural (GUILHERME \& DIETZ, 2014; ORTÍZ, 2002) and decolonial discursive practices (MIGNOLO, 2013) are enacted in a Portuguese as an Additional Language classroom in a transborder context at the Federal University of Latin American Integration (UNILA) located in the city of Foz do Iguaçu, Paraná, Brazil in the Triple Border with Paraguay and Argentina - and also, this paper aims at how these practices can make visible the students' and the professor's performative identities (PINTO, 2007) in a Portuguese as an Additional Language classroom at UNILA. These discursive practices were uttered through oral presentations produced by the students for a final paper assigned in the discipline of Portuguese as an Additional Language. The theme of these oral presentations was the Paraguay War or the Triple Alliance War occurred in South America in the nineteenth century. As a result, these activities, which were applied in a Portuguese as an Additional Language classroom at UNILA, rearranged, recombined and made visible the students' and the professor's performative identities through the translingual, transcultural and decolonial practices. 


\section{Revista do SELL}

v. 6 , no. 3

ISSN: $1983-3873$

KEYWORDS: Decolonial Studies; Performative Identities; Portuguese as an Additional Language; Transculturalities; Translanguaging; UNILA

\section{CONSIDERAÇÕES INICIAIS}

As aulas de Língua Portuguesa Adicional ${ }^{1}$ na Universidade Federal da Integração Latino-Americana (UNILA), compostas pelo professor brasileiro e por aprendizes de países hispânicos e francófonos da América Latina e do Caribe, são espaços privilegiados onde as culturas em movimento e as performances identitárias manifestadas pelas práticas locais de linguagens (PENNYCOOK, 2010) potencializam a busca pelo ouvir as "vozes do Sul". A universidade, que está localizada na cidade de Foz do Iguaçu, no Paraná, na Tríplice Fronteira entre Argentina, Brasil e Paraguai, conta com 20 nacionalidades latinoamericanas e caribenhas. Este rico espaço acadêmico latino-americano e caribenho fronteiriço possibilita-nos refletir, pensar e habitar a América Latina por meio de teóricos e estudiosos que também vieram do Sul ou que têm como cerne de suas pesquisas e estudos o "sulear"2 (FREIRE, 2015). Portanto, as relações norte-sul ou sul-norte podem ser reconfiguradas e problematizadas nesse espaço fluido, móvel e desterritorializado que é a sala de aula de Língua Portuguesa Adicional (PLA) na fronteira. Assim, as aulas de PLA na UNILA podem ser estudadas e apreendidas pelas lentes daqueles que sempre tiveram suas vozes apagadas por um sistema moderno/colonial que desumaniza e oprime. Por esta razão, meu lócus de trabalho permite-me criar diálogos entre meu lugar teórico e meu lugar político.

Destarte, este artigo pretende refletir sobre como as práticas translíngues (CANAGARAJAH, 2013; GARCÍA \& WEI, 2014), as transculturalidades (GUILHERME \& DIETZ, 2014; ORTIZ, 2002) e os estudos decoloniais (MIGNOLO, 2013) estão manifestados na sala de aula de PLA e como tais manifestações podem (in)visibilizar as identidades performativas (PINTO, 2007) dos alunos e do professor em contexto

\footnotetext{
${ }^{1}$ Adotamos o termo língua adicional neste artigo, corroborando a definição de Schlatter e Garcez (2009) para esse termo, para expressar que essa língua nos pertence e não é estrangeira para nós. Por isso, os estudantes escolhem adicioná-la aos seus repertórios linguísticos idiossincráticos com o objetivo de fazerem uso dela em suas práticas sociais. A visão desse termo valoriza a comunicação transnacional, isto é, aquela que transcende as fronteiras nacionais e que visam à inclusão cidadã para a justiça social, fazendo com que as dicotomias nativo/estrangeiro ou primeira/segunda língua percam seus significados.

${ }^{2}$ Freire (2015) usou esse termo decolonial "sulear" em referência ao termo "nortear" por uma mera questão ideológica. Neste caso, sua orientação começa pelo Sul, pelo local de onde viemos, sinalizando que o conhecimento também pode partir do Sul para o Norte.
} 


\section{Revista do SELL}

v. 6 , no. 3

ISSN: $1983-3873$

transfronteiriço ${ }^{3}$. Esses diálogos translíngues, transculturais e decoloniais serão estimulados por meio de apresentações orais como trabalho final da disciplina de Português Língua Adicional. Tais textos versam sobre um importante e grande evento que marcou para sempre a história da América Latina, sobretudo o Cone-Sul latino-americano; a Guerra do Paraguai, também conhecida como Guerra de la Triple Alianza. Esperamos, assim, que as atividades aplicadas no contexto de sala de aula de PLA possam, por meio das práticas translinguajeiras, transculturais e decoloniais recombinar, ressignificar e visibilizar as identidades performadas pelos sujeitos aprendizes e pelo professor, abrindo possibilidades para que transitem por uma multiplicidade de lugares e colaborem ativamente nas diversas redes configuradas pelos territórios transnacionais.

O artigo está organizado nas seguintes seções: primeiramente, discorremos sobre os diálogos teóricos que fundamentaram este trabalho; na segunda seção, fazemos uma apresentação metodológica, contemplando o tipo e o cenário da pesquisa, a geração de registros e seus sujeitos. Em seguida, na terceira seção, colocaremos os diálogos teóricos em ação por meio das análises das práticas translinguajeiras, transculturais e decoloniais manifestadas na sala de aula de Língua Portuguesa Adicional, na Tríplice Fronteira mais movimentada do país. Por fim, teceremos as considerações finais.

\footnotetext{
3 Pereira Carneiro (2016) discute os construtos de regiões transfronteiriças e transfronteirizações como conceitos em construção. O primeiro seria caracterizado pela porosidade existente nas regiões entre dois ou mais países, onde a abertura prevalece sobre o fechamento, um lugar vivo, dinâmico e complexo que prepara o terreno para os processos de transfronteirizações, quando seus habitantes transcendem as fronteiras, valorizando e incorporando em suas estratégias de vida, hábitos que já não podem mais ser limitados a um país ou outro.
} 


\section{Revista do SELL}

v. 6 , no. 3

ISSN: $1983-3873$

\section{DIÁlogos QUE FUNDAMENTAM AS PRÁtICAS TRANSLÍNGUES ${ }^{4}$, TRANSCULTURAIS E DECOLONIAIS}

O termo translíngue para Canagarajah (2013) significa a possibilidade que temos de fazer uso de variados recursos linguísticos e semióticos em nossas práticas locais visando à comunicação. "Nós devemos notar, portanto, que a comunicação como uma prática tranlíngue envolve uma mudança fundamental sobre a maneira como a comunicação é teorizada nas orientações modernas e monolíngues" (CANAGARAJAH, 2013, p. 27). Inclusive a gramática e o significado são redefinidos por meio das práticas translíngues locais. Devemos considerar também quais são as ideologias linguísticas que estão por trás das práticas translíngues. Portanto, considerar práticas locais translíngues e suas respectivas ideologias já é uma quebra ou ruptura de paradigma. Rompimento este que desconstrói e descoloniza o status quo colonizador, dominante, predominante e monolíngue no que se refere às linguagens e às políticas e ideologias que as definem, encaixando-as dentro de um modelo estático e estanque.

Seguindo essa mudança de paradigma linguístico, político e ideológico, García e Wei (2014) constroem o que chamam de translinguagens. Para eles, as translinguagens são manifestadas quando um sujeito faz uso de todo o seu repertório linguístico, não se importando se ele estará se comunicando no que culturalmente, politicamente e socialmente convencionou-se chamar de língua inglesa, língua espanhola, língua francesa, língua portuguesa etc. Este construto traz a ideia de que não sabemos uma língua totalmente. $O$ que sabemos ou possuímos são repertórios dessas línguas

\footnotetext{
${ }^{4}$ Apesar de algumas críticas (EDWARDS, 2012; ORMAN, 2013), que consideram esses termos -trans como "vinho velho em garrafas novas" ou como "verborragia infértil e improdutiva" ao invés de uma "ruptura epistemológica", corroboramos o fato de que as práticas translíngues existem antes mesmo das invenções e construções do que convencionou-se chamar de línguas (CANAGARAJAH, 2013). Ele afirma que as práticas translíngues sempre estiveram presentes e vivas no cotidiano do Ocidente, do Oriente e das comunidades indígenas autóctones de todo o planeta. Essas comunidades sempre utilizaram de variados repertórios e recursos linguísticos e semióticos para se comunicarem, mas elas sempre foram desconsideradas e escondidas pelos discursos dominantes e legitimadores do poder. Para Canagarajah (2013, p. 33), o que é considerado como saber legitimado na academia ocidental está longe do que realmente acontece fora dos muros escolares, das pesquisas e das academias. "O que temos são novas teorias, mas não novas práticas" (CANAGARAJAH, p. 33. 2013). Devemos levar em consideração o que Pennycook (2017) observa sobre o risco de incorporarmos as práticas translíngues ou as translinguagens nas caixinhas da sociolinguística ortodoxa. Devemos estar sempre vigilantes para que isso não aconteça, evitando assim, considerarmos as translinguagens como um bilinguismo ou multilinguismo tradicional, em que as línguas são consideradas como sistemas autônomos, não-dinâmicos, estanques e segmentados.
} 


\section{Revista do SELL}

v. 6 , no. 3

ISSN: $1983-3873$

(BLOOMAERT, 2010). A ideia das translinguagens para eles está fundamentada no conceito de linguagem de Maturana e Varela (1998), em que a linguagem se auto criará e recriará em contato com ela própria e com o contexto que a envolve. Tal contexto também se recriará em razão de seu contato com essa linguagem. Esse processo de auto-criação e auto-reprodução visa à sobrevivência da própria linguagem que anseia por comunicação. E a ideia do prefixo -trans nos remete ao ir além do construto monolíngue, estanque e não dinâmico das linguagens. Ir além também do bilinguismo e multilinguismo que consideram as línguas como dois ou mais sistemas autônomos, separados, segmentados e não dinâmicos. As translinguagens de García \& Wei (2014) têm o objetivo de fazer com que as vozes que estão apagadas pelo sistema colonial moderno sejam ouvidas, trazendo os trans-sujeitos para os holofotes da inclusão que visa à transformação e que ruma para a justiça social.

Por esta razão, nós dialogamos com Ortíz (2002) e Guilherme \& Dietz (2014) para falarmos sobre transculturação e com Mignolo (2013) para aplicarmos os conceito decolonial chamado pensamento fronteiriço ou pensamento liminar. A linguagem relacionada a esses trans-conceitos enfatizará e focará uma nova e transformadora prática, produzido por um novo trans-sujeito. A linguagem associada aos trans-conceitos, possibilitará a transformação da sala de aula convencional em um entre-lugar novo, fluido e transgressivo. O antropólogo cubano Fernando Ortíz, por meio de sua obra "Contrapunteo cubano del tabaco y del azúcar", de $1940^{5}$, introduziu o conceito de transculturação (transculturación), referindo-se ao complexo e multidirecional processo na transformação cultural cubana

Nesse conceito de transculturação está o âmago do questionamento da pureza epistemológica das línguas autônomas, enunciadas por aqueles que detêm o poder, como os indivíduos de grupos sociais e nacionais. Assim, a transculturação não é simplesmente uma adaptação passiva a um padrão local ou cultural estático. A transculturação dissolve diferenças para criar novas realidades. Não são duas identidades fixas que são combinadas. A transculturação é um espaço que cria uma nova realidade porque nenhuma parte da equação é vista como estática ou dominante, mas sim operando dentro de uma rede dinâmica de transformações culturais. Este novo espaço onde se dará o concerto

\footnotetext{
${ }^{5}$ Esta obra possui inúmeras traduções. Neste trabalho, utilizamos a tradução para o inglês feita em 2002.
} 


\section{Revista do SELL}

v. 6 , no. 3

ISSN: $1983-3873$

transgressivo na sala de aula é o entre-lugar (BHABHA, 2004) ou a terceira margem ${ }^{6}$, que está fundamentado no diálogo teórico da transculturação. Entretanto, quando Ortíz (2002) fala em transculturação, ele ainda está dentro dos limites da nação. Portanto, ampliaremos a transculturação de Ortíz (2002) utilizando o que Guilherme e Dietz (2014) chamam de incompletude das culturas. Para eles, o diálogo transcultural transcende os lugares comuns de cada cultura, objetivando aumentar a consciência de incompletude recíproca ao máximo possível mediante à participação no diálogo com um pé em um cultura e o outro na outra. É como se transcendêssemos as fronteiras de Ortíz (2002) e passássemos a considerar as culturas em trânsito constante em um mundo cada vez mais desterritorializado. Tomando como base a saída dos alunos não brasileiros de seus países para virem estudar na UNILA, o transcultural (GUILHERME \& DIETZ, 2014) é o ponto onde a interação entre diferentes culturas pode transcender não somente suas extremidades, mas também seus interiores, criando terceiros lugares, terceiras margens, e entre-lugares, dando lugar a um novo espaço cultural.

Para que as manifestações translíngues, transculturais e decoloniais sejam manifestadas no espaço transgressivo da sala de aula na fronteira trinacional mais movimentada do Brasil, criando seus entre-lugares e terceiras margens, ainda falta trazer para o diálogo o pensamento decolonial do argentino Walter Mignolo, que afirma que a transculturação envolve o pensamento liminar ou fronteiriço e a colonialidade. Mignolo vê o pensamento liminar como o pensamento concebido fora das fronteiras do sistema mundial moderno/colonial (MIGNOLO, 2013, p. 11) e como o pensamento entre duas línguas e suas relações históricas (MIGNOLO, 2013, p. 74). O pensamento liminar atesta que há conexões entre o lugar de onde se teoriza e os lugares de onde se estabelece politicamente nossos lugares de enunciação. Mignolo vê o estabelecimento político de "uma outra língua" como

\footnotetext{
${ }^{6} \mathrm{O}$ termo "terceira margem" é retirado do conto de João Guimarães Rosa, presente no livro "Primeiras Estórias" (ROSA, 2015), em que ele narra a história de um pai que, um dia, resolve adentrar um rio em uma canoa, e ali permanecer, para sempre. A terceira margem pode ser um terceiro lugar, que não é nem a margem direita e nem a margem esquerda do rio, podendo ser a canoa a própria terceira margem. Ela também pode ser a eternidade, ou seja, aquilo que todos presenciamos pode ser apenas o inconsciente ou o delírio do narrador-personagem que é filho do pai que está na canoa. Por fim, a terceira margem também pode ser o desconhecido, ou a busca interior, autoconhecimento. A necessidade que o pai tem de se buscar por meio do isolamento. Portanto, a terceira margem é tanto um "entre-lugar" como um "não-lugar" ou como um terceiro lugar que surge de encontros, fluidez e hibridizações. O encontro, diálogo e trânsito entre diferentes culturas na sala de aula de PLA pode criar muitas "terceiras margens". A terceira margem não seria nem o lugar do opressor/colonizador que oprime, nem o lugar do oprimido que sofre a opressão (FREIRE, 2013), mas o lugar da constante busca pela libertação, onde oprimido e opressor transformam-se seres em libertação.
} 


\section{Revista do SELL}

v. 6 , no. 3

ISSN: $1983-3873$

uma maneira de romper com os projetos globais para desenvolver "um outro pensamento", um entre-lugar, uma terceira margem. Esta "outra língua", que caracteriza a terceira margem, tem o objetivo de descolonizar os saberes intelectuais dominantes, incluindo as linguagens. Mignolo (2013) chama este pensar entre línguas de bilinguajar. Para ele, bilinguajar é uma forma de viver entre duas ou mais línguas, de existir, de lutar, de se estabelecer politicamente, de sobreviver e de permanecer em um mundo ditado por um sistema colonial/moderno, tal qual o conceito de bilinguismo dinâmico proposto por García (2009). É uma maneira de inclusão das línguas não dominantes visando à transformação e à libertação sociais e acadêmicas. Ele também afirma que este bilinguajar só será possível se considerarmos a linguagem de Maturana e Varela (1998) como prática cultural e como luta pelo poder desde a perspectiva da diferença colonial, isto é, desde a perspectiva decolonial, de valorização dos saberes subalternos e decolonização dos saberes dominantes. E, por fim, Mignolo (2013) considera o fato de que a transculturação de Ortíz (2002) seja também considerada pelas lentes simbólicas da representação dos poderes coloniais que estão em cena. $O$ fato de estarmos utilizando de vários autores teóricos latinoamericanos neste texto para a construção de um espaço transgressivo em sala de aula de Língua Portuguesa Adicional em contexto de fronteira também reflete este entre-lugar de descolonização dos saberes dominantes. Mignolo afirma que essa "outra língua", que ele chama de bilinguajamento, transforma o local de enunciação (MIGNOLO, 2013, p. 220). É a partir dessa posição liminar, fronteiriça e transcultural de práticas sociais e ações "entre" duas línguas que não são mais estáticas ou vinculadas a uma identidade nacional é que, de acordo com García e Wei (2014), surge o que elas chamam de translinguagem. Para elas, na translinguagem o falante está situado em um espaço onde representações e enunciações alternativas podem ser geradas por meio de histórias que são desenterradas e libertadas para serem ouvidas e onde saberes conflituosos são produzidos. Para Garcia \& Wei (2014), a translinguagem refere-se às práticas sociais e ações que estabelecem um processo político de transformações sociais e subjetivas, que, por sua vez, relembrando o processo autopoiético do linguajamento, produz translinguagens. Além de desafiar a visão das línguas como autônomas e puras, a translinguagem, como um produto do pensamento liminar/fronteiriço, do saber subalterno e marginalizado concebido a partir de um entre-lugar bilíngue, muda o local de enunciação e resiste às assimetrias de poder que os "códigos bilíngues" criam com frequência. 


\section{Revista do SELL}

v. 6 , no. 3

ISSN: $1983-3873$

E para finalizarmos o diálogo, tais conceitos expostos acima podem estimular as possíveis visibilidades das identidades performativas (PINTO, 2007) dos sujeitos na sala de aula de PLA em contexto transfronteiriço. Pinto (2007) propõe reutilizar o conceito de identidades não fixas, e não pré-estabelecidas, mas constituídas nas e pelas práticas discursivas, sendo performadas pelos sujeitos. Portanto, ela pensa em um conceito mais abrangente de identidade linguística, considerando a identidade performativa. Ela sugere $o$ deslocamento do conceito de identidade linguística para o conceito de identidade performativa. Tal discussão pode ser estendida para quaisquer tipos de identidade, como por exemplo, as identidades dos sujeitos presentes neste artigo. Pinto (2007) primeiro define o que é performatividade ou linguagem performativa para então enveredar pelo conceito de identidade performativa. Para ela, performatividade é " ... a capacidade de ação operada pelo ato de fala na sua materialidade plena - sonora e corporal." (PINTO, 2007). $O$ ato de fala e não o enunciado é o que permite e obriga o sujeito a se constituir enquanto tal. $O$ ato de fala compreende o que é dito, quem diz, como é dito, como o corpo diz e como o enunciado diz. Assim, a linguagem autopoiética (MATURANA \& VARELA, 1998) que fundamenta os conceitos de translinguagem (GARCÍA \& WEI, 2014) e bilinguajar e pensamento fronteiriço (MIGNOLO, 2013), também fundamenta o conceito de identidade performativa (PINTO, 2007), pois a linguagem não reflete o lugar social de quem fala, mas faz parte desse lugar. Ela tanto produz o lugar social como também é produzida por ele. Por isso, a identidade performativa não preexiste à linguagem. Os sujeitos marcam suas identidades, performando-as assídua e repetidamente, sustentando o "eu" e o "nós". Para Pinto (2007), a repetição é necessária para sustentar a identidade precisamente porque esta não existe fora dos atos de fala que a sustentam. Por fim, ao discorrer sobre as identidades performativas, Pinto (2007) afirma:

"Se assumirmos a performatividade como o que obriga o sujeito a se constituir em processo, a identidade de falante é também performativa, ou seja, não existe senão na prática e na história de sua própria exibição- e é por isso mesmo sempre múltipla, fragmentada, e repetível." (PINTO, 2007, p. 16)

A seguir, discorreremos sobre a metodologia da pesquisa, contemplando o contexto, a geração de registros e os sujeitos envolvidos nesse estudo translíngue, transcultural e decolonial. 


\section{POR UMA METODOLOGIA TRANSGRESSIVA: 0 CONTEXTO} TRANSFRONTEIRIÇO, A GERAÇÃO DE REGISTROS E OS TRANS-SUJEITOS DA PESQUISA

Esta pesquisa pertence à área da Linguística Aplicada Transgressiva (PENNYCOOK, 2006), pois tem como objetivo ampliar e transpor as fronteiras do conhecimento por meio da decolonização epistêmico-metodológica. Esta é uma pesquisa de natureza qualitativa, apresentando como base metodológica o interpretativismo cujo paradigma de interpretação é o estudo de caso.

É importante ressaltar que este artigo faz parte de um trabalho mais amplo, que é a minha pesquisa de Doutorado. Portanto, apresentarei aqui apenas uma pequena parte do universo de sujeitos e dos registros gerados nesse contexto.

Esta seção divide-se em três subseções. Na primeira subseção, apresentamos o contexto onde a pesquisa foi desenvolvida, para então, na segunda subseção, dicorrermos sobre a geração de registros. Por fim, na terceira subseção, apresentamos os transsujeitos.

\subsection{O CONTEXTO TRANSFRONTEIRIÇO}

O Brasil, país de tamanho continental com mais de 8,5 milhões de $\mathrm{km}^{2}$, possui 10 municípios situados em tríplices fronteiras. Dentre elas, encontramos a Tríplice Fronteira entre o Brasil, a Argentina e o Paraguai considerada a mais movimentada e populosa, em razão de seu caráter turístico e de sua configuração econômica e politicamente estratégica. Do lado argentino, está a cidade de Puerto Iguazú, na Província de Misiones com aproximadamente 80.020 habitantes, do lado paraguaio, localiza-se Ciudad Del Este, na Província de Alto Paraná, a segunda maior cidade do Paraguai e maior cidade desta Tríplice Fronteira, contando com aproximadamente 387.000 pessoas e, do lado brasileiro, a cidade de Foz do Iguaçu, no Estado do Paraná, separada de Puerto Iguazú pelo rio Iguaçu e de Ciudad Del Este pelo rio Paraná.

Foz do Iguaçu possui uma população de 263.915 habitantes, conforme estimativa do Instituto Brasileiro de Geografia e Estatística (IBGE), de agosto de 2016. É conhecida internacionalmente pelas Cataratas do Iguaçu - uma das vencedoras do concurso que escolheu as 7 Maravilhas da Natureza - e pela Usina Hidrelétrica de Itaipu, a segunda maior 


\section{Revista do SELL}

v. 6 , no. 3

ISSN: $1983-3873$

do mundo em tamanho e primeira em geração de energia, que em 1996 foi considerada uma das 7 Maravilhas do Mundo Moderno pela Sociedade Americana de Engenheiros Civis. É considerada, ainda, um dos municípios mais multiculturais do Brasil, onde estão presentes habitantes de mais de $80^{7}$ nacionalidades, entre estas italianos, alemães, ucranianos, japoneses, árabes, haitianos, sendo as mais representativas a libanesa, a chinesa, a paraguaia e a argentina.

Nesse cenário, foi criada A Universidade Federal da Integração Latino-Americana (UNILA), pela Lei no 12.189/2010, cuja vocação contempla a pluralidade linguística e cultural da região, ou seja, sua vocação é o intercâmbio acadêmico e a cooperação solidária com países integrantes do Mercosul e com os demais países da América Latina e do Caribe, em áreas consideradas estratégicas para o desenvolvimento e a integração regionais.

De acordo com a seção III do Regimento Geral da universidade, quando discorre sobre o Ciclo Comum de Estudos, este é parte integrante da missão da UNILA e obrigatório a todos os discentes matriculados na graduação, contemplando-se os seguintes conteúdos:

(i) Estudo Compreensivo sobre a América Latina e Caribe (Fundamentos da América Latina); (ii) Epistemologia e Metodologia e (iii) Línguas Adicionais Portuguesa e Espanhola. Seguindo estas orientações, os alunos brasileiros cursam Língua Espanhola Adicional e os alunos estrangeiros cursam Língua Portuguesa Adicional. As disciplinas do Ciclo Comum de Estudos são cursadas em três semestres. No caso das Línguas, os estudantes têm que cursar os três primeiros níveis, quais sejam, os níveis básico, intermediário I e intermediário II. O nível avançado é destinado para aqueles que queiram se aprofundar nos estudos linguístico-culturais. Para participar da seleção internacional com o intuito de conquistar uma vaga nos 29 cursos de graduação oferecidos pela UNILA, os alunos não brasileiros devem preencher um formulário eletrônico disponível na página da instituição com suas informações pessoais e anexar diversos documentos exigidos para esse processo, como carteira de identidade, certidão de nascimento, certificado de conclusão de Ensino Médio, histórico de notas e uma ficha de declaração. Além da conclusão do Ensino Médio, esse candidato deverá ser maior de dezoito anos e não portar nenhum tipo de visto do Brasil. Ele também não necessita ter conhecimento em Língua Portuguesa, pois um curso de acolhimento linguístico-cultural é oferecido à distância para esses candidatos. Todo o

\footnotetext{
7 Disponível em http://www.pmfi.pr.gov.br/conteudo/\%3bjsessionid\%3d62b17adaaee52db1094cf08d8af7?idMenu=1004, acesso em 20/04/2017.
} 


\section{Revista do SELL}

v. 6 , no. 3

ISSN: $1983-3873$

processo de seleção é gratuito. Almejando a uma formação superior de excelência destinada ao desenvolvimento e integração latino-americanos, os atuais 3.575 estudantes da UNILA são oriundos de 20 países, abarcando a América do Sul, a América Central, o Caribe e a América do Norte.

\subsection{A GERAÇÃO DE REGISTROS}

A análise aqui proposta recai sobre textos orais produzidos pelos alunos das disciplinas de Língua Portuguesa Adicional dos níveis Básico. Os estudantes do nível Básico tiveram que apresentar uma comunicação oral sobre o documentário $A$ Última Guerra do Prata, que versa sobre a Guerra do Paraguai ${ }^{8}$, documentário que foi 0 instrumento de geração dos registros para esta pesquisa. O documentário "A Última Guerra do Prata", produzido pela TV Escola em parceria com a empresa Digitallcine no ano de 2014, foi destinado ao púbico em geral, abarcando as áreas temáticas da História, da Sociologia e da Geografia. A série traz um novo olhar sobre a polêmica Guerra do Paraguai; um trágico conflito em que morreram mais de 350 mil pessoas. A partir de visitas aos locais que sediaram campos de batalhas, análises de historiadores e consultas a documentos e fotografias raras, a série revela os interesses geopolíticos que conduziram ao conflito, o cotidiano de homens e mulheres que estiveram no teatro de guerra, e ainda, a influência que a Guerra do Paraguai teve na formação das nações que hoje integram o Mercado Comum do Sul (Mercosul).

A turma de nível básico foi dividida em quatro grupos; cada um representando um país envolvido na Guerra do Paraguai. Cada grupo deveria falar sobre a perspectiva do país que ele representaria, bem como sobre o conteúdo de algum episódio do documentário. Por exemplo, o grupo 1 falou sobre a perspectiva uruguaia e sobre o que foi dito no primeiro episódio. $\mathrm{O}$ grupo dois falou sobre a perspectiva paraguaia e sobre 0 conteúdo do segundo episódio. O grupo 3 falou sobre a perspectiva argentina e sobre o

\footnotetext{
${ }^{8}$ Este documentário foi escolhido para esta pesquisa por dois motivos. Primeiro, por ser um documentário que traz diferentes visões da guerra pelas lentes dos quatro países envolvidos, quais sejam, a Argentina, o Brasil, o Paraguai e o Uruguai, dando-nos um panorama geral que vai desde a formação dos seus Estados Nacionais até as causas, desenvolvimento e consequências do conflito para os países envolvidos. Segundo, por ter sido um evento que teve sérias consequências para todos os quatro países que formam o Cone Sul latino-americano, principalmente para o Paraguai, sendo a cidade de Foz do Iguaçu um ponto estratégico para esta guerra, por estar localizada na Tríplice Fronteira entre a Argentina, o Brasil e o Paraguai e, por isso, possuindo várias ruas e escolas com nomes de personagens que combateram na guerra.
} 


\section{Revista do SELL}

v. 6 , no. 3

ISSN: $1983-3873$

que foi dito no terceiro episódio, enquanto o grupo 4 falou sobre a perspectiva brasileira e sobre o conteúdo do quarto episódio. Para os alunos que não eram de nacionalidades envolvidas no conflito, foi pedido que eles expusessem sobre algum conflito que seu país vivenciou com outro e que opinassem sobre a Guerra do Paraguai. Por exemplo, os alunos colombianos expuseram sobre conflitos em que a Colômbia esteve envolvida contra o Peru e o Equador, por exemplo, enquanto os bolivianos e paraguaios expuseram sobre os conflitos entre a Bolívia e o Paraguai. Já os alunos de nacionalidades envolvidas no conflito também deveriam expor suas percepções sobre a guerra.

As apresentações orais dos alunos foram gravadas em áudio .mp3 e também foram filmadas para fins de registro para as futuras análises.

\subsection{OS TRANS-SUJEITOS DA PESQUISA}

Licenciado em Língua Inglesa pela Universidade Federal de Minas Gerais (UFMG) e mestre em Estudos de Linguagens com foco no ensino-aprendizagem de Língua Portuguesa Adicional pelo Centro Federal de Educação Tecnológica de Minas Gerais (CEFET-MG), sou professor do quadro efetivo da UNILA de Língua Portuguesa Adicional. Este artigo contempla discentes estrangeiros oriundos do nível básico de Língua Portuguesa Adicional. As aulas aconteceram no primeiro semestre de 2016.

Os sujeitos desta pesquisa são de diversos países da América Latina e do Caribe, quais sejam, Bolívia, Colômbia, Equador e Paraguai, e todos eles cursam as disciplinas de Língua Portuguesa Adicional da UNILA. Foram considerados excertos translíngues dos seguintes alunos do nível básico: um aluno equatoriano, pertencente ao curso de Engenharia Civil; uma aluna equatoriana do curso de Biotecnologia; uma aluna boliviana, pertencente ao curso de Ciências Econômicas - Economia, Integração e Desenvolvimento; e um aluno paraguaio, do curso de Engenharia de Energias Renováveis.

A seguir, analisaremos os registros gerados, com o objetivo de valorizar e empoderar as "vozes do Sul", as vozes dos que vêm "de baixo" e que são marginalizadas pelos discursos e sistemas dominantes e colonizadores. Tal decolonização epistêmicometodológica nos leva à inclusão desses alunos para a transformação, cujo objetivo máximo é a justiça social. 


\section{Revista do SELL}

v. 6 , no. 3

ISSN: $1983-3873$

\section{ANÁLISE DAS PRÁTICAS TRANSLÍNGUES:}

Todos os excertos a seguir foram produzidos pelo professor e pelos alunos do nível básico da disciplina de Língua Portuguesa Adicional, pertencente ao Ciclo Comum de Estudos da UNILA. O excerto a seguir foi produzido pelo professor brasileiro, pelo aluno equatoriano do curso de Engenharia Civil e pela aluna equatoriana do curso de Biotecnologia.

Aluno equatoriano: "Eu só vou dar mi perspectiva desde el punto de vista de Equador. É... Equador não se intervino nesta guerra. Equador formou uma quádrupla aliança... Equador só hizo eso, mas não intervino."

Professor: "Quádrupla? Mas com quem?"

Aluno equatoriano: "era uma aliança que tenía Lationoamérica..."

Professor: "Outra guerra isso, né?"

Aluno equatoriano: No! La guerra del Plata...

Professor: "Teve alguma guerra que o Equador apoiou a Colômbia contra o Peru ou vice versa, Peru e Equador contra a Colômbia?"

Aluna equatoriana: "Colômbia robó nosso território. Peru robó nosso território!"

Neste excerto, o aluno equatoriano dá a sua perspectiva do seu país Equador na Guerra do Paraguai. Foi pedido aos alunos que não fossem argentinos, paraguaios ou uruguaios, que relacionassem a Guerra do Paraguai com seu país ou que também falassem de outras guerras vivenciadas por seus países. Sabe-se que este conflito envolveu diretamente quatro países, quais sejam, Brasil, Argentina, Uruguai e Paraguai, sendo que os três primeiros países formaram uma Tríplice Aliança contra o Paraguai. $O$ aluno equatoriano dá a perspectiva do Equador na guerra e, de acordo com ele, o Equador formou uma quádupla aliança com os países que já compunham a Tríplice Aliança, isto é, com a Argentina, com o Brasil e com o Uruguai. Entretanto, para dar essa informação o aluno fez uso de todo o seu repertório linguístico, utilizando palavras e expressões ora em língua portuguesa, ora em língua espanhola, como por exemplo, "mi perspectiva desde el punto de vista", "hizo", "eso", "intervino", "tenía Latinoamérica", la Guerra del Plata entre outras, caracterizando a translinguagem (GARCÍA \& WEI, 2014) e o pensamento fronteiriço ou liminar de Mignolo (2013), uma vez que pensar, viver e habitar entre as línguas é uma forma 


\section{Revista do SELL}

v. 6 , no. 3

ISSN: $1983-3873$

de resistência ao discurso colonizador monolíngue e, ao mesmo tempo, uma maneira de lutar pelo empoderamento das vozes marginalizadas do Sul. O uso dessa prática translíngue nos remete ao que Canagarajah (2013) diz sobre o rompimento do paradigma monolíngue, decolonizando o status quo dominante em que temos uma língua para uma nação e uma variedade ou dialeto para uma região. É essa linguagem autopoiética (MATURANA \& VARELA, 1998) que permitirá a construção do contraponto transcultural (ORTíZ, 2002), quando surge um entendimento novo, um dado contingente, que nem o professor sabia. Por esta razão, o professor pergunta a que guerra o aluno colombiano estava se referindo. Nota-se que, após a resposta do aluno, dizendo que era uma aliança "que tenía Latinoamérica" o professor ainda insiste, perguntando se isso era outra guerra e o aluno responde: "No! La Guerra del Plata". É interessante notar aqui que o aluno, por meio de sua translinguagem (GARCÍA \& WEI, 2014) traz um dado novo transcultural (ORTíZ, 2002) para todos na sala de aula, inclusive para o professor. Tal fato corrobora a ideia de que os alunos também ensinam aos professores e aos outros alunos, corroborando a linguagem como prática social e dialógica, enquanto os professores também aprendem com os alunos. Esse dado novo se reflete no transcultural justamente pelo fato de ele advir do contato do aluno equatoriano com um tema que envolvia outras culturas, como as paraguaias, brasileiras, uruguaias e argentinas. Aqui, trazemos Guilherme e Dietz (2014) para a análise, pois esse dado novo sobre a Guerra do Paraguai trazido pelo aluno equatoriano só foi possível em razão do trânsito das culturas dentro da sala de aula de PLA. Tal trânsito foi alimentado pela incompletude das culturas, e por isso, pela necessidade de elas sempre estarem em movimento, em busca de outras culturas que as possam fazê-las ampliar não somente suas fronteiras como também seus interiores, criando assim, terceiras margens e entre-lugares. E esses contatos se deram na fronteira, trazendo-nos a ideia de que a fronteira não só limita ou obstaculiza, mas pode ser um espaço fluido, líquido e poroso que também abre nossas mentes para outras perspectivas e possibilidades, por isso, transfronteira, sendo aquela que vai além dos seus muros, que transpõe as barreiras e amplia os horizontes e que inclui outras culturas. Toda essa nova informação, esse entrelugar, essa terceira margem, só foi possível porque o aluno equatoriano utilizou seu repertório translíngue. Ao fazer uso desse repertório, o aluno empodera sua voz equatoriana, até então ausente do discurso oficial sobre a Guerra, que inclui somente quatro nacionalidades. Ao enunciar e visibilizar essa identidade equatoriana, ele produz efeitos que constroem aquilo que ele alega dizer em um ato de fala iterável e ritualizado e 


\section{Revista do SELL}

v. 6 , no. 3

ISSN: $1983-3873$

isso fez com que ele resgatasse sua voz que deu vida e visibilidade à sua identidade performativa (PINTO, 2007). Essa sua identidade foi construída na e pela sua prática translíngue no momento de sua fala. Ela não foi pré-concebida, mas sim construída no e pelo seu discurso translíngue. A seguir, o professor pergunta se houve outra guerra, além da Guerra do Paraguai, em que o Equador apoiou a Colômbia contra o Peru ou se o Equador apoiou o Peru, ficando contra a Colômbia. Nota-se aqui que o professor instiga os alunos a falarem mais sobre outros conflitos. Aqui, o professor performa sua identidade de sujeito provocador no sentido de estimular os alunos a interagirem na sala de aula. A partir de então, uma aluna equatoriana responde que o Peru "robó" o território equatoriano e também afirma que a Colômbia "robó" o território equatoriano ${ }^{9}$. Neste caso, a identidade performativa (PINTO, 2007) da estudante foi manifestada por meio de sua translinguagem (GARCÍA \& WEI, 2014). Cabe ao professor ter sensibilidade inter/transcultural para saber negociar esses ruídos e tensões advindos dos constantes trânsitos e interações que ocorrem entre as diversas culturas na sala de aula de PLA em contexto transfronteiriço. Tais movimentos entre as culturas não estão livres de alguns choques ocasionais. $O$ professor de PLA deve promover o pensamento crítico por meio da desconstrução dos saberes dominantes no sentido de valorizar e escutar as vozes dos outros, exercitando suas alteridades a fim de enaltecerem suas visões etnorrelativistas em detrimento de suas visões etnocêntricas.

O excerto seguinte foi produzido pelo professor brasileiro, por uma aluna boliviana do curso de Ciências Econômicas - Economia, Integração e Desenvolvimento e por um aluno paraguaio do curso de Engenhria de Recursos Renováveis.

Aluna boliviana sobre a Guerra do Chaco: "Vou falar um pouco da guerra entre Paraguai e Bolívia, não sei como a eles les eseñan... A nós nos fala que, a verdade nós esquecimos de eso território e quando Paraguai vino para ahí foi mais um descuido de nós..."

Professor: "O território já era paraguaio ou boliviano?"

Aluna boliviana: "Era boliviano!"

Alunos paraguaios: "Era paraguaio!"

\footnotetext{
${ }^{9}$ Não houve mais registros desta aluna para explorarmos um pouco mais o que a ela quis dizer com "robó". Sua reação foi tão enfática e passional que ela optou por não mais discorrer sobre o assunto.
} 


\section{Revista do SELL}

v. 6 , no. 3

ISSN: $1983-3873$

Aluna boliviana: "Segundo me enseñaron era boliviano..."

Aluno paraguaio: "Sobre a perspectiva que me ensinaram, a Bolívia perdiu a guerra contra o Chile. Então, não tinha saída sob o mar, não tinha rios, não tinha saída. Então, fueron para o Chaco para tomar e ali eles ficariam com o rio Paraguai para sair para o mar, mas ainda assim não conseguiram..."

Outra aluna boliviana: "El Chaco ya era contestable desde la Guerra de la Triple Alianza.

Como foi pedido aos alunos que não tivessem suas nacionalidades diretamente relacionadas à Guerra do Paraguai que também falassem sobre os conflitos de seus países, a aluna boliviana começou a discorrer sobre a Guerra do Chaco ${ }^{10}$. Em sua construção da autopoiesis (MATURANA \& VARELA, 1998) contínua, interminável e processual que caracteriza a prática translíngue a aluna boliviana inicia seu discurso ressaltando o que a eles bolivianos "les eseñan" sobre a Guerra do Chaco. Segundo a estudante boliviana, eles são informados de que a Bolívia se esqueceu ou se descuidou "de eso" território, o que fez com que o Paraguai "vino para ahí" e tomasse o território deles. Há vários aspectos que podemo analisar aqui sobre esta primeira fala. A aluna boliviana por meio da transculturação traz um dado novo e contingente para todos nós na sala de aula em contexto transfronteiriço que é a Guerra do Chaco. Esse trânsito entre as culturas possibilitou o surgimento de terceiras margens, isto é, partindo da Guerra do Paraguai, descobrimos dados sobre a Guerra do Chaco por meio do diálogo, interação e tensão entre as culturas boliviana e paraguaia na sala de aula de PLA na fronteira. Esse diálogo transcultural transcendeu os lugares comuns das nossas culturas (GUILHERME \& DIETZ, 2014), principalmente, por ser a primeira vez, que muitos alunos ouviram sobre a Guerra do Chaco, com exceção dos alunos bolivianos e paraguaios, diretamente envolvidos nesse conflito. Baseamo-nos aqui nas suposições culturais descentralizadas e incompletas, corroborando o fato de que as culturas buscam por diálogos, principalmente em uma sala de aula de PLA fronteiriça. Por isso, é interessante que os movimentos entre as culturas reconceitualizem e estabeleçam novos lugares de interseção. Como consequência dessa nova informação, todos na sala de aula, inclusive o professor, aprenderam com a aluna

\footnotetext{
${ }^{10}$ A Guerra do Chaco foi um conflito armado entre a Bolívia e o Paraguai que se estendeu de 1932 a 1935. Originou-se pela disputa territorial da região do Chaco Boreal, tendo como uma das causas a descoberta de petróleo no sopé dos Andes.
} 


\section{Revista do SELL}

v. 6 , no. 3

ISSN: $1983-3873$

boliviana sobre um importante fato histórico para as culturas bolivianas e paraguaias. $\mathrm{O}$ aprendizado desse fato novo também abre nossos horizontes no sentido de que estamos habitando, sentindo e vivendo entre as várias línguas presentes na fronteira. Fronteira esta que nos permite decolonizar os saberes dominantes (MIGNOLO, 2003) e valorizar outros saberes que não sejam aqueles aos quais estamos acostumados e habituados a ouvir, como por exemplo, saber sobre esse importante conflito que foi a Guerra do Chaco. Tudo isso caracteriza esse entre-lugar e essa terceita margem líquida e fluida que é a sala de aula de língua portuguesa adicional em contexto transfronteiriço. Outro aspecto está ressaltado no fato de a aluna boliviana, por meio de sua prática translíngue visibilizar não somente sua identidade performativa (PINTO, 2007), como também a de todos os outros alunos bolivianos quando ela diz que "a nós nos fala que". Aqui, devemos nos alertar para o perigo das identidades essencializadas, isto é, aquelas que já foram pré-estabelecidas e preconfiguradas. Quando ela afirma que ela aprendeu assim na Bolívia, ela acaba por reforçar um discurso que parece já ter sido estabelecido e oficializado como legítimo. A performatividade também pode reforçar um discurso já estabelecido. A partir desse discurso da aluna boliviana, o professor pergunta se, antes da Guerra do Chaco, o território já era paraguaio ou boliviano. A aluna boliviana reafirma sua identidade performativa por meio do seu discurso, enquanto os alunos paraguaios afirmam suas identidades performativas por meio dos seus discursos, dizendo que "era paraguaio". Mais uma vez, a aluna boliviana reafirma e performa sua identidade por intermédio de seu discurso translíngue: "Segundo me eseñaron era boliviano". A partir de então, o aluno paraguaio do curso de Engenharia de Energias Renováveis responde à pergunta feita pelo professor, afirmando em seu discurso translíngue que, na perspectiva que ensinaram a ele, a Bolívia "perdiu" a guerra contra o Chile. Ainda segundo seu discurso translíngue, por eles, os bolivianos, não terem mais saída para o mar, "fueron" para o Chaco visando tomar o rio Paraguai para saírem para o mar e, ainda assim, não conseguiram. Neste discurso, o aluno paraguaio performa sua identidade por meio de seu discurso translíngue, trazendo para todos nós informações novas transculturais que advieram de seu contato com a cultura boliviana, com a sua cultura paraguaia e com outras culturas envolvidas no conflito, como a chilena. A seguir, a aluna boliviana dá visibilidade à sua identidade performativa, por intermédio de seu discurso em língua espanhola, dizendo que "El Chaco ya era contestable desde la Guerra de la Triple Alianza!" Com esse discurso, a aluna boliviana relativizou toda a questão, afirmando que essa região do Chaco já era disputável entre a Bolívia e o 


\section{Revista do SELL}

v. 6 , no. 3

ISSN: $1983-3873$

Paraguai desde a Guerra do Paraguai ou desde a "Guerra de la Triple Alianza". Interessante notar aqui que o prinicipal assunto das apresentações orais, a Guerra do Paraguai, dos alunos volta à discussão, sendo relacionada a essa nova informação que é a Guerra do Chaco. Importante ressaltar também o fato de a Guerra do Paraguai apresentar outros nomes, como por exemplo, "Guerra de la Triple Alianza" no Paraguai, talvez pelo fato de este nome colocar a responsabilidade da guerra como um conflito causado pela Tríplice Aliança e não pelo Paraguai. No Brasil, quando falamos Guerra do Paraguai, pode também nos dar a impressão de que o conflito foi causado pelo Paraguai. Todos esses discursos podem ser desconstruídos por meio do pensar entre as línguas, vivendo, habitando e decolonizando os saberes dominantes sobre esses conflitos. Cabe ao professor sensibilizar e problematizar todas essas interessantes questões juntamente com os alunos para que todos possam resgatar suas vozes do Sul desempoderadas por meio de seus discursos translíngues, transculturais e decoloniais empoderando-as nesse cenário emancipatório e libertador (FREIRE, 2013) que é a sala de aula de língua portuguesa adicional em contexto transfronteiriço.

\section{CONSIDERAÇÕES FINAIS}

Este artigo trouxe reflexões sobre como as translinguagens (CANAGARAJAH, 2013; GARCÍA \& WEI, 2014), as transculturalidades (ORTÍZ, 2002; GUILHERME \& DIETZ, 2014) e os estudos descoloniais (MIGNOLO, 2013) foram manifestados na sala de aula de PLA e como tais manifestações puderam (in)visibilizar as identidades performativas (PINTO, 2007) dos alunos e do professor em conteto transfronteiriço. Esperamos, assim, que as atividades aplicadas no contexto de sala de aula de PLA possam, por meio das práticas translinguajeiras, transculturais e descoloniais recombinar, ressignificar e visibilizar as identidades performadas pelos sujeitos aprendizes e pelo professor, pelas "vozes do Sul", que vêm "de baixo", abrindo possibilidades para que transitem por uma multiplicidade de lugares e colaborem ativamente nas diversas redes configuradas pelos territórios transnacionais.

Dessa forma, houve espaço para o uso multilíngue dos alunos e professor em sala de aula, compreendendo-se que a prática translíngue é muito mais do que um apoio para o aprendizado, sendo também uma maneira diferente de olhar para as interações como expressivas, transformacionais e inclusivas, visando à justiça social. 


\section{Revista do SELL}

v. 6 , no. 3

ISSN: $1983-3873$

Por meio das diversas translinguagens presentes e produzidas por alunos de origens diversas, este artigo apresentou como a flexibilidade dessas translinguagens pode contribuir para que os alunos tomem a sua voz, transformando-os para lidarem não somente com o ambiente acadêmico onde se encontram, com todos os seus prós e contras, mas também os preparando para os enfrentamentos locais, globais, políticos, sociais e culturais que podem vir a ocorrer em um mundo que, infelizmente, revela-se cada vez mais adverso, desrespeitoso, preconceituoso e rude, principalmente para com aqueles que sempre tiveram suas vozes, línguas e direitos apagados e desvalorizados pelo status quo vigente. As translinguagens produzidas em sala de aula e expostas neste artigo tornam evidente que não se pode separar as práticas de linguagem da maneira como percebemos o mundo, nossa autopoiesis (MATURANA \& VARELA, 1998). Torna evidente também a necessidade de assumir um entre-lugar, uma terceira margem legítima, caracterizada pela adaptabilidade às crateras e cumes da conversação, caracterizada pelo espaço e realidade novos e contínuos que vão surgir da interação entre diferentes culturas - a transculturação (ORTÍZ, 2002; GUILHERME \& DIETZ, 2014) - pela flexibilidade e pela resistência às assimetrias de poder (MIGNOLO, 2013) instaladas pelas práticas linguísticas padronizadas da escola ou da universidade.

Destarte, nasce a urgência em discutirmos, cada vez mais, os papéis das políticas linguísticas, de novas epistemologias nas culturas acadêmicas, de práticas pedagógicas e de sistemas educacionais que não mais consideram as línguas como sistemas obedientes às estruturas dominadoras modernas/coloniais autônomas, fechadas e segmentadas. Não obstante, devemos discutir a necessidade da inclusão das minorias que foram apagadas ou silenciadas pelos discursos dominantes e colonizadores nos espaços transnacionais e transfronteiriços das salas de aula. Não precisamos estar em uma fronteira geográfica para discutirmos todas essas questões. A valorização dos dicursos translíngues presentes em sala de aula pode sensibilizar os estudantes e os professores a habitarem as fronteiras, sejam elas físicas ou emocionais. Podem sensibilizá-los a sentir, a pensar, a performar e a visibilizar a fronteira, não como um lugar que separa e fragmenta, mas sim como um espaço que une, que integra, que inclui e que transforma para a justiça social, estejam esses transsujeitos onde estiverem. As fronteiras também habitam dentro de nós mesmos. 


\section{Revista do SELL}

v. 6 , no. 3

ISSN: $1983-3873$

\section{REFERÊNCIAS}

BHABA, H.K. O local da cultura. Belo Horizonte: Editora UFMG, 2004.

BLOMMAERT, J. The sociolinguistics of globalization. Cambridge: Cambridge University Press, 2010.

CANAGARAJAH, S. Translingual Practice: Global English and Cosmopolitan Relations. New York: Routledge, 2013.

EDWARDS, J. Multilingualism: Understanding Linguistic Diversity. London: Continuum, 2012.

FREIRE, P. Pedagogia do Oprimido. Rio de Janeiro: Paz e Terra, 2013.

FREIRE, P. Pedagogia da Esperança. Rio de Janeiro: Paz e Terra, 2015.

GARCÍA, O. Bilingual education in the $21^{\text {st }}$ Century: A global perspective. Malden: Wiley-Blackwell, 2009.

GARCÍA, O.; WEI, L. Translanguaging: Language, Bilingualism and Education. New York: Palgrave MacMillan, 2014.

GUILHERME, M.; DIETZ, G. Diferencia en la diversidad: perspectivas múltiples de complejidades conceptuales multi, inter y trans-culturales. In: Estudios sobre las Culturas Contemporáneas, vol. XX, núm. 40, Colima: 2014, p. 13-36.

MATURANA, H.; VARELA, F. The Tree of knowledge: the biological roots of human understanding. Boston and London: Shambhala, 1998.

MIGNOLO, W. L. Histórias locales/diseños globales: Colonialidad, conocimientos subalternos y pensamieto fronterizo. Madrid: Ediciones Akal, S.A., 2013.

MINISTÉRIO DA EDUCAÇÃO; UNIVERSIDADE FEDERAL DA INTEGRAÇÃO LATINOAMERICANA. Estatuto da UNILA. 2012.

ORMAN, J. "New Lingualisms, Same Old Codes." Language Sciences. 37: 90-98, 2013.

ORTíZ, F. Contrapunteo cubano del tabaco y el azúcar. Madrid: Cátedra, 2002.

PENNYCOOK, A. "Uma linguística aplicada transgressiva. In: MOITA LOPEZ, L.P. Por uma linguística aplicada indisciplinar. São Paulo: Parábola Editorial, 2006.

PENNYCOOK, A. Language as Local Practice. London: Routledge, 2010.

PENNYCOOK, A. Language Policy and Local Practices. In: GARCÍA, O.; FLORES, N.; SPOTTI, M. "The Oxford Handbook of Language and Society". New York: Oxford University Press, 2017. 


\section{Revista do SELL}

v. 6 , no. 3

ISSN: $1983-3873$

PEREIRA CARNEIRO, C. Fronteiras irmãs: transfronteirizações na Bacia do Prata. Porto Alegre: Editora Ideograf, 2016.

PINTO, J.P. Conexões teóricas entre performatividade, corpo e identidades.

D.E.L.T.A: 23:1, 2007.

ROSA, J. G. Primeiras estórias. Rio de Janeiro: Nova Fronteira, 2015.

SCHLATTER, M.; GARCEZ, P. Referenciais Curriculares para o Ensino de Língua

Espanhola e de Língua Inglesa. Rio Grande do Sul: Secretaria de Educação do Estado, 2009.

Sítio oficial da Universidade Federal da Integração Latino-Americana (UNILA). Disponível em: http://unila.edu.br. Acesso em: 04 de abril de 2017.

http://www.pmfi.pr.gov.br/conteudo/\%3bjsessionid\%3d62b17adaaee52db1094cf08d8af7?i $d M e n u=1004$. Acesso em 20/04/2017. 